ISSN 2466-2232

Online ISSN 2466-2100

\title{
Microtexture and Microstructural Evolution of Friction Stir Welded AA5052-H32 Joints
}

\author{
Young-Bin Lim*, and Kwang-Jin Lee,, \\ *Korea Institute of Industrial Technology, Jeonju, 54853, Korea \\ †Corresponding author : kjlee@kitech.re.kr \\ (Received January 24, 2019 ; Revised February 7, 2019 ; Accepted February 26, 2019)
}

\begin{abstract}
In this study, analysis was performed on the microstructural change in the friction stir welding (FSW) region of AA5052-H32 thin sheets. The micro texture and microstructure in the stir zone (SZ) and base metal were characterized using the electron back-scattered diffraction (EBSD) technique and transmission electron microscopy (TEM) observation. The grain size and misorientation angle distribution were also investigated. The hardness profile of the FSW region with the microstructure in each area was discussed. The grains in the stir zone were more refined than those of the base metal. The base metal has $\{001\}<100>$ textures, while the stir zone takes a $\{112\}<110>$ textures attributed to the severe shear deformation during FSW. The TEM observation results suggest that recrystallization during the friction stir welding process diminishes the density of dislocation in the SZ. It is also considered that the drop of hardness in the SZ is caused by the decrease of dislocation density, even though the grains were refined.
\end{abstract}

Key Words : Friction stir welding, AA5052-H32, EBSD, Texture, Microstructure

\section{Introduction}

Exhaust gas emission regulations and the need for energy saving are contributing to an increased demand for weight-reduction and better fuel-efficiency in transportation industries. As a promising method to solve these issues, the application of light-weight materials is desired. Among the various light-weight materials, aluminum alloys are an appropriate material due to their features of light weight, corrosion resistance, specific strength, good formability, and recycling efficiency ${ }^{1-4)}$. In particular, the $5 \mathrm{xxx}$ series of aluminum alloys with magnesium have reasonable strength and good formability. For this reason, studies on the application of the $5 \mathrm{xxx}$ series aluminum for strengthening parts of auto bodies have been performed ${ }^{5}$. In this case, new and reliable welding and joining processes are required because the Al alloys are generally classified as difficult materials to weld due to the solidification of cracks, segregation, and porosities in the fusion zone during conventional fusion welding.

In recent years, friction stir welding (FSW), invented by the welding Institute (TWI) ${ }^{6}$ has attracted attention as a promising alternative joining method. FSW is a solid-state joining method that involves a rotating, non-consumable tool with a specific design. The tool is plunged into the materials, and makes local changes in the stirred zone due to both the mechanical deformation and the frictional heat. This method leads to fewer metallurgical defects and less distortion, compared with conventional fusion welding, because it is conducted under the melting temperature of the base metal ${ }^{7)}$. Due to its many advantages, FSW has attracted a great deal of attention in various industrial fields.

Many studies ${ }^{8-11)}$ of FSW for $5 \mathrm{xxx}$ series aluminum have been performed. However, most of these focus on mechanical properties such as tensile strength, hardness, and formability. The microstructure in the welding region should be controlled to obtain better mechanical properties. The microstructural evolution in the stir zone (SZ) should be investigated to control the microstructure.

In the present study, 1mm-thick AA5052-H32 butt joints are manufactured by FSW. The microstructures of the welding region are precisely investigated. In particular, microstructural changes in the stir zone after the FSW

Journal of Welding and Joining, Vol.37 No.2(2019) pp35-40

https://doi.org/10.5781/JWJ.2019.37.2.6 
are evaluated and discussed on the basis of electron back-scattered diffraction (EBSD) measurement and transmission electron microscopy (TEM) observations. Additionally, the hardness test in the mid-cross-section is also conducted to investigate the change of mechanical properties.

\section{Experimental procedures}

As a base metal, commercial AA5052-H32 alloy of $1 \mathrm{~mm}$ in thickness was used in this study. The chemical composition of the base metal is shown in Table 1 . Rectangular strips $(100 \mathrm{mmL} \times 50 \mathrm{mmW})$ were prepared from the base metal sheets. The strip surface subjected to the butt welding was cleaned with alcohol and dried before FSW. The tool for FSW was made of high-speed tool steel (SKD61). The shoulder and pin diameter of the tool are $8 \mathrm{~mm}$ and $2.5 \mathrm{~mm}$, respectively. The pin length was $0.8 \mathrm{~mm}$. The tool was traversed parallel to the rolling direction of the base metal with a $2^{\circ}$ tilt from the vertical axis.

For generating sufficient frictional heat, the dwell time of the tool was $5 \mathrm{sec}$ before starting FSW. A backing plate made of structural mild steel was used.

FSW was performed at tool rotation speed ranges and traverse welding speed ranges of 600 2000 RPM and $8 \sim 12 \mathrm{~mm} / \mathrm{s}$, respectively. After evaluating the mechanical properties of FSW joints, the optimized condition was selected to $1500 \mathrm{RPM}$ and $12 \mathrm{~mm} / \mathrm{s}$. Sound joints without defects were obtained.

After FSW, the transverse cross-sections of the joints were observed with an optical microscope (Olympus, GX51). The samples for optical microscopy were prepared according to the standard procedures including grinding polishing, and then etched using a solution of $15 \mathrm{ml} \mathrm{HF}+10 \mathrm{ml} \mathrm{H}_{3} \mathrm{PO}_{4}+75 \mathrm{ml} \mathrm{H}_{2} \mathrm{O}$. For electron backscattered diffraction (Zeiss, SUPRA 40VP) investigation, the specimens were electro-polished at $253 \mathrm{~K}$ and $30 \mathrm{~V}$ in a solution containing $2 \mathrm{vol} \%$ nitric acid, 5 vol\% perchloric acid, and methanol in order to remove the deformed layer. The EBSD investigation was performed on the normal-direction plane of the base metal and the central region of the stir zone with the TSLOIM package. For precise investigation, $2 \mu \mathrm{m}$ and 0.5 $\mu \mathrm{m}$ step sizes were used for the base metal and the stir

Table 1 Chemical composition of the base metal AA5052H32

\begin{tabular}{|c|c|c|c|c|c|c|c|}
\hline \multicolumn{7}{|c|}{ Alloying element (wt $\%)$} \\
\hline $\mathrm{Si}$ & $\mathrm{Fe}$ & $\mathrm{Cu}$ & $\mathrm{Mn}$ & $\mathrm{Mg}$ & $\mathrm{Cr}$ & $\mathrm{Zn}$ & $\mathrm{Al}$ \\
\hline 0.21 & 0.27 & 0.02 & 0.03 & 2.25 & 0.18 & 0.02 & Bal. \\
\hline
\end{tabular}

zone, respectively. The grains were identified from the presence of continuous boundaries of above $15^{\circ}$ misorientation. For TEM (FEI, TECNAIF-20), specimens of $3 \mathrm{~mm}$ in diameter were cut from the base metal and the stir zone using an electrical discharging method. The thin foils were prepared by a precision ion polishing system. A Vickers' micro-hardness test (Mitutoyo, HM112) was performed in the mid-thickness region across the cross-section under a load of $100 \mathrm{~g}$ for a $10 \mathrm{~s}$ dwell time at room temperature.

\section{Results and discussion}

Fig. 1 shows a low magnification overview of the cross-section of the friction-stir-welded AA5052-H32 joint. Defect-free joints were obtained; cracks or porosities were not observed in the stir zone. Also, thermal distortion did not occur. The bowl-shaped stir zone is clearly visible. Distinct regions were observed in the typical friction stir weld, which indicate different microstructures.

Fig. 2 indicates the optical microstructures at locations 'A', ' $\mathrm{B}$ ', and ' $\mathrm{C}$ ' shown in Fig. 1. The 'A' region is termed the base metal, which did not undergo plastic deformation and thermal effect with the FSW process. In the ' $A$ ' region, a rolling structure is observed in the center region and a recrystallized structure in both the surface and bottom regions. It is considered that the partially recrystallized microstructure in the ' $A$ ' region resulted from the insufficient stabilizing process after cold rolling. However, the microstructures in ' $\mathrm{B}$ ' and ' $\mathrm{C}$ ' differ to that of 'A'. Location ' $\mathrm{B}$ ', known as the thermo- mechanically affected zone (TMAZ), has morphological changes in the grain structure. This zone is found in close vicinity to the stir zone, where the region experiences metal flow as well as thermal cycling during the FSW process. However, this region has not undergone recrystallization. Location ' $\mathrm{C}$ ' shows the stir zone, which has a fine and equiaxed grains structure, compared with that of the base metal. This region has experienced direct frictional heat and plastic deformation through the rotation and travel of the tool. Consequently, recrystallization has occurred in this region. This recrystallized area is occupied by the rotating tool pin. For a more detailed examination of the microstructures, EBSD and TEM analyses were performed.

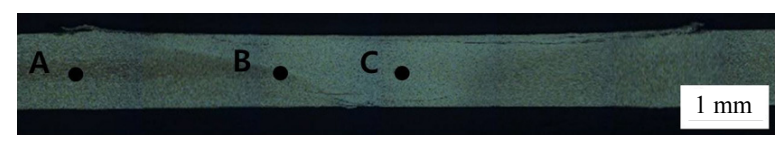

Fig. 1 Cross-section perpendicular to the welding direction of the FSW joint 
Fig. 3 shows the EBSD inverse pole figure (IPF) maps for the normal direction plane (ND-P) of the base metal and stir zone, respectively. The microstructural characterization differs somewhat between the base metal and the stir zone. The base metal has textures corresponding
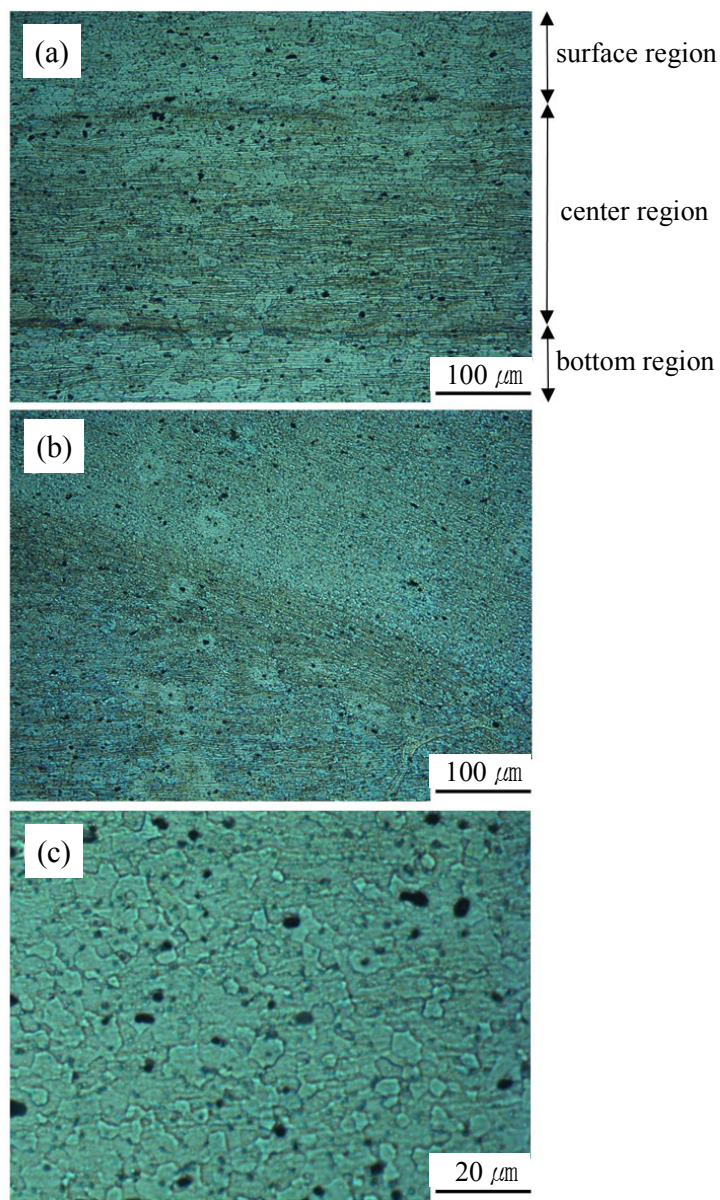

Fig. 2 Optical micrographs of the 'A', 'B', and ' $C$ ' regions as defined in Fig. 1
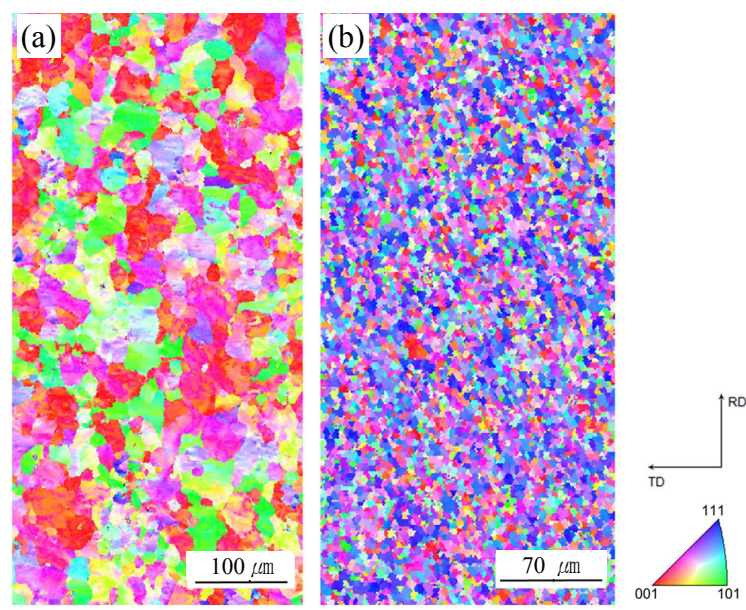

Fig. 3 EBSD Inverse pole figure maps for (a) base metal and (b) stir zone to $\{001\} \perp \mathrm{ND}$, while the center of the stir zone shows $\{111\} \perp$ ND. This change results from the intense shear deformation by tool rotation during FSW. The grains in the stir zone were more refined than those of the base metal.

Fig. 4 shows the considerable difference in grain size and misorientation angle distribution between the base metal and the stir zone. The base metal region exhibits a relative coarse grain structure with an average grain size of $28 \mu \mathrm{m}$, while the stir zone consists of fine grains with an average grain size of $6 \mu \mathrm{m}$, as shown in Fig 4(a). This grain refinement is due to the breakup of the original grain structure because of the intense plastic deformation and frictional heat by the rotation and travel of the tool during FSW. Fig. 4(b) shows the misorientation angle distribution of the base metal and the stir zone. In general, the grain boundaries can be classified into high or low angle grain boundaries, as those having misorientation of more than $15^{\circ}$ and those having misorientation less $15^{\circ}$, respectively. From the comparison

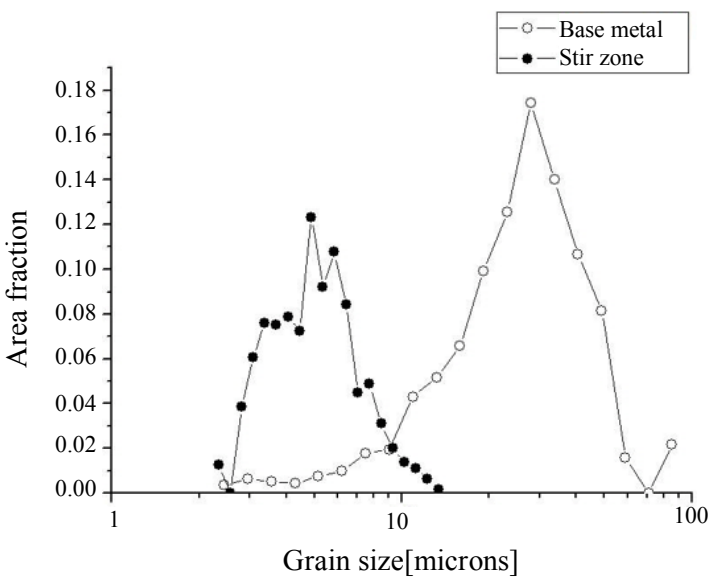

(a)

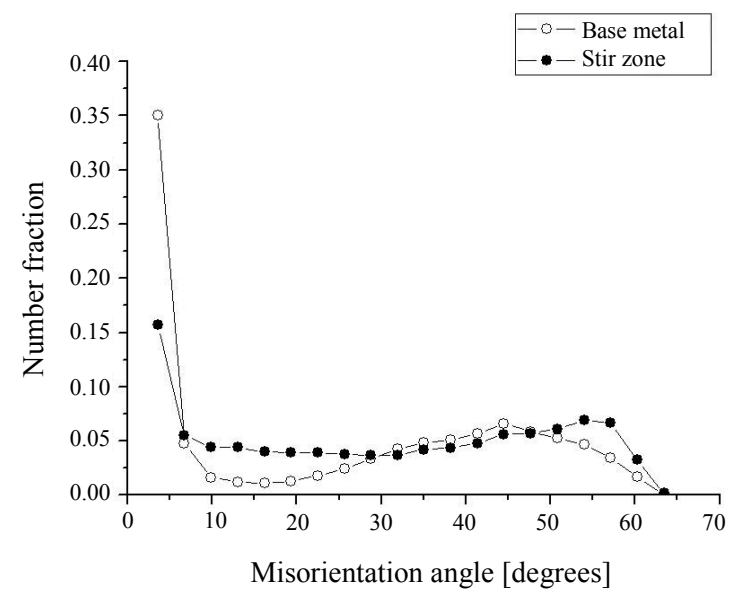

(b)

Fig. 4 Grain size (a) and misorientation angle (b) distribution 
of misorientation angle distribution between the base metal and stir zone, it is seen that the fraction of high angle grain boundaries (HAGB) is much higher in the stir zone. The higher fraction of HAGB in the stir zone is connected with the development of recrystallized grains during the FSW. During the plastic deformation, subgrains are formed by recovery. The subgrain boundaries change to a high angle, and consequently those grains having HAGB are formed by the process of recrystallization $^{12)}$.

Fig. 5 shows (111) pole figures for the base metal and stir zone. The base metal takes a component containing $\{001\}<100>$ Cube orientation. The Cube orientation is known as a typical recrystallized texture in the cubic

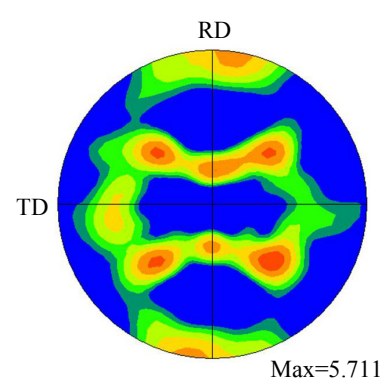

(a)

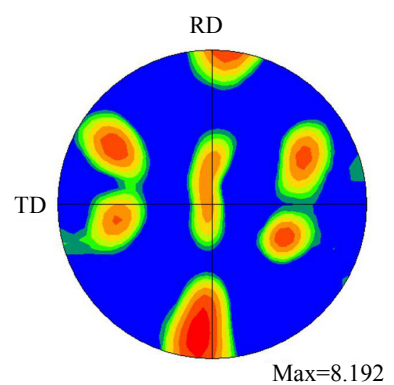

(b)
Fig. 5 (111) pole figures show microtexture for the base metal (a) and the stir zone (b)
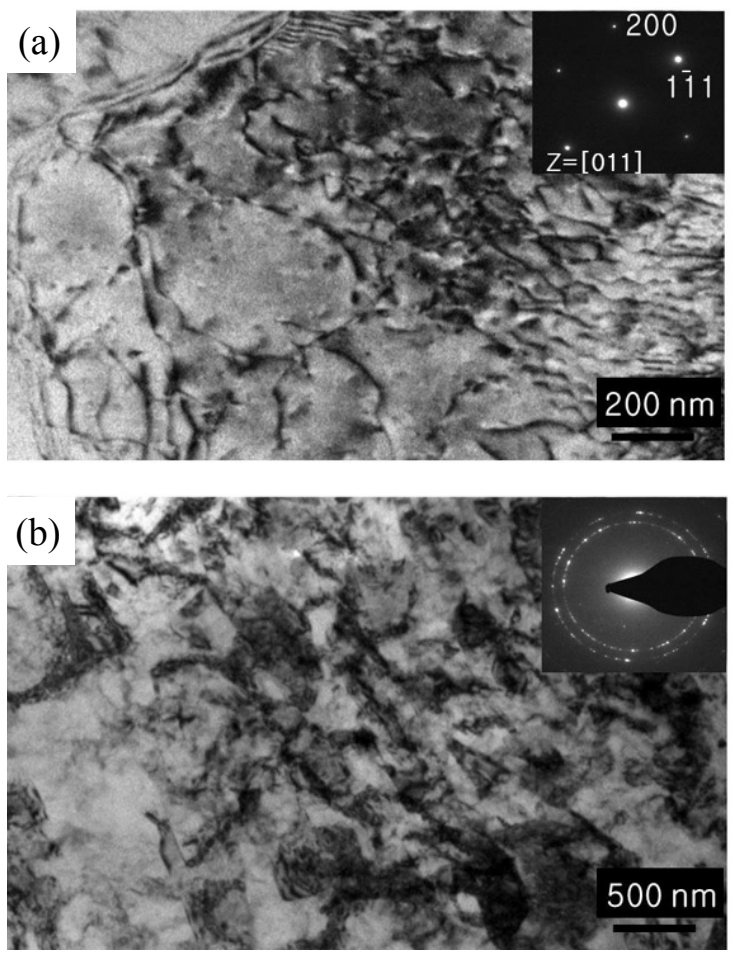

Fig. 6 TEM micrographs of the base metal (a) and the center of the stir zone (b) structured materials. In addition, the base metal indicates a component with $\{112\}<111>$ Copper orientation. This is a typical rolling deformation texture of the materials have face-centered cubic crystal (FCC) similar to $\mathrm{Al}$ and $\mathrm{Cu}$. The textures of the base metal show they are manufactured with H32-temper. The H32 condition involves both strain hardening such as cold rolling and stabilizing by relatively low temperature heating to obtain $1 / 4$ hard of the material. On the other hand, a very different texture was formed in the stir zone. The $\{112\}$ $<110>$ texture was mainly confirmed in the stir zone. This is the simple shear deformed texture. The formation of the $\{112\}<110>$ texture in the stir zone is attributed to the severe shear deformation during FSW. For FCC metals, the common plane and the common direction are $\{111\}$ and $\langle 110\rangle$, respectively. A shear deformation in $\mathrm{Al}$ occurs by slip in the $<110>$ direction on $\{111\}$ planes. For this reason, two partial fiber textures develop after the shear deformation: $\{111\}<\mathrm{uvw}>$ (called $a$ fiber) and $\{h \mathrm{kl}\}<110>$ (called $\beta$ fiber). Also, a metastable texture $\mathrm{C}$ is formed, which takes a component with a $\{110\}<001>$ texture. From these results and discussion, it was clearly revealed that a $\{112\}<110>\beta /-\beta$ fiber texture is developed in the stir zone.

Fig. 6 shows transmission electron micrographs of the base metal and the stir zone after FSW. The corresponding selected area diffraction pattern (SADP) of the stir zone indicates the Debye ring pattern as shown in Fig. 6(b). This means that the stir zone consists of ultra-fine grains, the result of which tends to agree well with the results of the EBSD data shown in Fig. 3(b) and Fig. 4(a). Also, a high density of dislocation was observed in the base metal. It was considered that these dislocations had been introduced by the manufacturing process of cold rolling. On the other hand, the TEM observation in

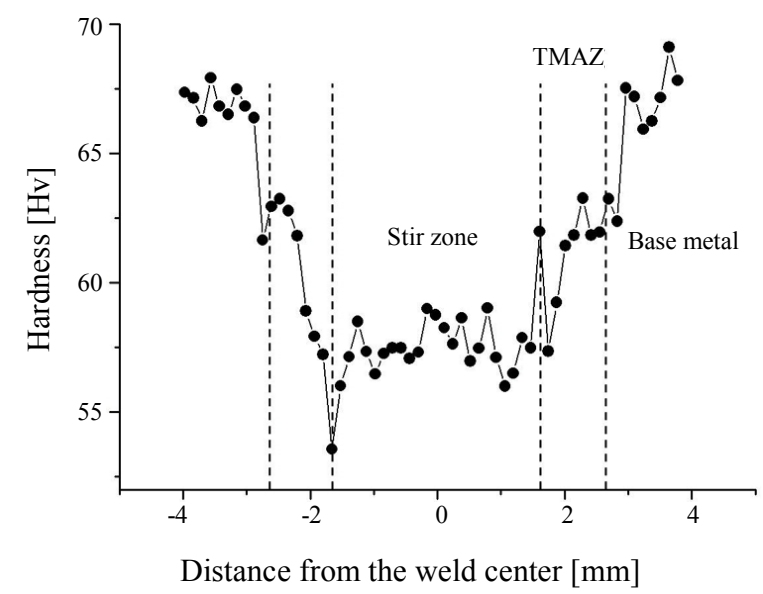

Fig. 7 Hardness profile in the mid-cross-section of FSW region 
the stir zone shows a markedly lower density of dislocations compared with that of the base metal. One of the possible reasons for this result is the occurrence of recrystallization due to the severe shear plastic deformation and frictional heat by the rotation and travel of the tool during FSW. Fig. 7 shows the hardness profile in the mid cross-section of the friction stir welding region. The hardness in the base metal is approximately $67 \mathrm{Hv}$. On the other hand, the hardness of the stir zone varies from 53 to $57 \mathrm{Hv}$. It was revealed that the stir zone becomes softer than the base metal. Several factors such as dislocations, precipitates, and grain refining affect the hardness value of $\mathrm{Al}$ alloys. The 5xxx series $\mathrm{Al}$ alloys are classified as a group of non-heat treatable alloys. Therefore, the precipitates have little or no effect on hardness change in the stir zone. During FSW, the dislocations could be removed by both recovery and recrystallization, as shown in Fig 6. As a result, it is considered that the extinction of dislocation contributed to the decrease of hardness in the stir zone. The grain size of the stir zone was much smaller than that of the base metal. However, the hardness value of the stir zone was lower than that of the base metal. Based on these results, in the case of work-hardened non-heat treatable $5 \mathrm{xxx}$ series Al alloys, the dominant factor affecting the hardness distribution in the stir zone is the density of dislocation, not the grain size.

\section{Conclusions}

Friction stir welding of AA5052-H32 thin sheets was successfully performed without defects in the welding region. The microstructural evolutions in the stir zone are precisely examined by EBSD investigation and TEM observation. Many useful results were obtained and observations were made. The stir zone forms an ultra-fine grain microstructure consisting of equiaxed and recrystallized grains. The microtexture analysis by EBSD clearly revealed that the $\{112\}<110>\beta /-\beta$ simple shear deformation texture forms in the central region of the stir zone. The TEM observation for the stir zone shows relatively lower density of dislocations compared with that of the base metal. This is believed to be caused by the recovery and recrystallization due to the severe shear plastic deformation and sufficient frictional heat by the rotation and travel of the tool during FSW. In the case of work-hardened non-heat treatable $5 \mathrm{xxx}$ series $\mathrm{Al}$ alloys, it was revealed that the dominant factor affecting hardness distribution in the stir zone is the density of dislocation, not the grain size.

\section{Acknowledgement}

This work was supported by the R\&D program of the Korea Institute of Industrial Technology. Part of this work was also supported by the R\&D project (P0002251) of the Ministry of Trade, Industry and Energy.

ORCID: Young-Bin Lim: http://orcid.org/0000-0003-2392-9405 ORCID: Kwang-Jin Lee: http://orcid.org/0000-0002-1010-0078

\section{References}

1. N.K. Kim, B.C. Kim, Y.G. An, B.H. Jung, S.W. Song and C.Y. Kang, The Effect of Material Arrangement on Mechanical Properties in Friction Stir Welded Dissimilar A5052/A5J32 Aluminum Alloys. Metals and Materials International, 15 (2009) 671-675 https://doi.org/10.1007/s12540-009-0671-x

2. R. Narayanasamy, R. Ravindran, K. Manonmani and J. Satheesh, A crystallographic texture perspective formability investigation of aluminium 5052 alloy sheets at various annealing temperatures, Materials \& Design, 30 (2009) 1804-1817 https://doi.org/10.1016/j.matdes.2008.09.011

3. Z. Zhang, X. Yang, J. Zhang, G. Zhou, X. Xu and B. Zou, Effect of welding parameters on microstructure and mechanical properties of friction stir spot welded 5052 aluminum alloy, Materials \& Design, 32 (2011) 4461-4470 https://doi.org/10.1016/j.matdes.2011.03.058

4. V. Fahimpour, S. K. Sadrnezhaad and F. Karimzadeh, Corrosion behavior of aluminum 6061 alloy joined by friction stir welding and gas tungsten arc welding methods, Materials \& Design, 39 (2012) 329-333 https://doi.org/10.1016/j.matdes.2012.02.043

5. I.J. Polmear, Light alloys: From Traditional Alloys to Nanocrystals (4th Edition), Butterworth-Heinemann, UK (2005) 30

6. M.W. Thomas, E.D. Nicholas, J.C. Needham, M.G. Murch, P. Temple-smith and C.J. Dawes, Patent Applications 9125978.8, GB (1991), Patent 5460317, US (1995)

7. J.A. Schneider, Friction stir welding and processing (eds. R. S. Mishra and M. W. Mahoney), ASM International, USA (2007) 37

8. Y.S. Sato, Y. Sugiura, Y. Shoji, S.H.C. Park, H. Kokawa and K. Ikeda, Post-weld formability of friction stir welded Al alloy 5052, Materials Science and Engineering A, 369 (2004) 138-143 https://doi.org/10.1016/j.msea.2003.11.035

9. T. Hirata, T. Oguri, H. Hagino, T. Tanaka, S.W. Chung, Y. Takigawa and K. Higashi, Influence of friction stir welding parameters on grain size and formability in 5083 aluminum alloy, Materials Science and Engineering $A$, 456 (2007) 344-349 
https://doi.org/10.1016/j.msea.2006.12.079

10. Y.J. Kwon, S.B. Shim and D.H. Park, Friction stir welding of 5052 aluminum alloy plates, Transactions of Nonferrous Metals Society of China, 19 (2009) 23-27 https://doi.org/10.1016/S1003-6326(10)60239-7

11. S.O. Yoon, M.S. Kang, H.B. Nam, Y.J. Kwon, S.T. Hong, J.C. Kim, K.H. Lee, C.Y. Lim and J.D. Seo, Friction stir butt welding of A5052-O aluminum alloy plates,
Transactions of Nonferrous Metals Society of China, 22 (2012) 619-623 https://doi.org/10.1016/S1003-6326(12)61774-9

12. J.Q. Su, T.W. Nelson and C.J. Sterling, Microstructure evolution during FSW/FSP of high strength aluminum alloys. Materials Science and Engineering A, 405 (2005) 277-286

https://doi.org/10.1016/j.msea.2005.06.009 